\title{
The Effect of Activator to Binder Ratio on the Compressive Strength of Fly Ash Based Geopolymer Mortar in Sulphate Environment
}

\author{
Andi Arham Adam ${ }^{1 *}$, Suci Amalia Namira ${ }^{1}$, Atur PN Siregar ${ }^{1}$, and Mustofa ${ }^{2}$ \\ ${ }^{1}$ Departement of Civil Engineering, Tadulako University, Palu, Indonesia \\ ${ }^{2}$ Departement of Mechanical Engineering, Tadulako University, Palu, Indonesia
}

\begin{abstract}
One of the significant characteristic material needed to consider is durability. Sulphate ion contained in soil is one of aggressive agents that could cause degradation of concrete members which led to loss of compressive strength. The current research is to elaborate the effect of activator to binder ratio on the compressive strength of the fly ash based geopolymer mortar in the sulphate environment. Two different types of geopolymer mortar were casted i.e. mortar made of $100 \%$ fly ash and mortar contained $95 \%$ fly ash $+5 \%$ slaked lime. The fly ash used in this research is classified as $\mathrm{F}$ fly ash from the Mpanau power plant the variation of activator to binder ratio of $0.40 ; 0.50$; and 0.60 , and water/solid ratio variations of $0.32,0.34$ and 0.36 . The composition of sulfuric acid was by $5 \%$ of the sample volume. Geopolymers mortar compressive strength test is conducted on the immersed samples in a solution of $5 \%$ sulfuric acid with age of 0,7 , $14,28,56$, and 84 days, respectively. The compressive strength test results showed that the highest compressive strength of geopolymers mortar (resistant to sulfuric acid attack) was geopolymers mortar made from fly ash with activator to binder ratio 0.60 , water / solid ratio 0.32 , and percentage of lime to binder $5 \%$ at the age of 84 days.
\end{abstract}

\section{Introduction}

A lot of investigations has been conducted in order to find out mixing technology of cement based mortar by adding admixture agent as compliment to reduce cement use without ignoring the characteristics of cement mortar [1]

Geopolymers mortar is made of fine aggregate, fly ash, water and alkaline activator. Geopolymer mortar is a promising material in order to use as patching repair agent due to its highly beginning compressive strength, low permeability, high resistant of fire and aggressive ion, high compressive strength, and low shrinkage compared to conventional cement mortar [2], [3].

Mortar is a part of bonding matrix which is numerously used in structural and nonstructural constructions. The use of mortar in structural construction such as stone foundation, and in non-structural construction such as masonry wall construction.

* Corresponding author: adam.arham@gmail.com 
One of the important characteristics of the material that shall be considered is durability. In an aggressive environment, durability characteristic of used material is to resist sulphate attack in the soil and chloride ion attack in the groundwater [4]-[6]

Durability is the resilience of a structural element facing all conditions where it is designed to place, without any deterioration during the service period.

Every single deterioration of structural element is always related to durability quality of the material. In the aggressive environments, material will deteriorate at beginning by compound reaction of both materials and aggressive environments. The general physical damage is by showing cracks on the materials[6]. These cracks will induce increasing permeability and flow path of material. Increasing permeability of mortar and concrete tends to increase penetration of aggressive agent such as chloride ion into the structural element[7].

\section{Research methodology}

\subsection{Materials}

Some materials used in this research such as fly ash from PLTU Mpanau-Northern Palu, lime from Malotong, Ampana, Central Sulawesi, sodium silicate; sodium hydroxide, and fine aggregate used from Palu river shown below:

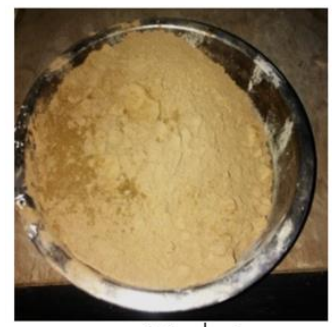

Fly ash

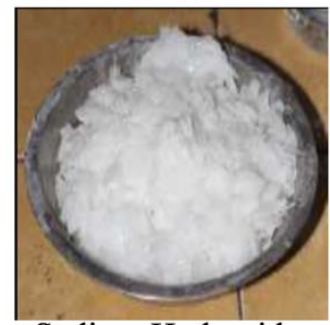

Sodium Hydroxide

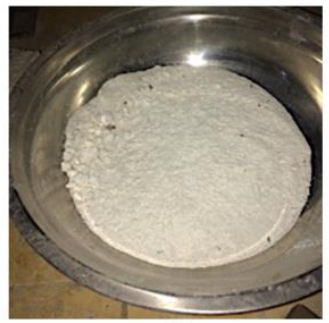

Lime

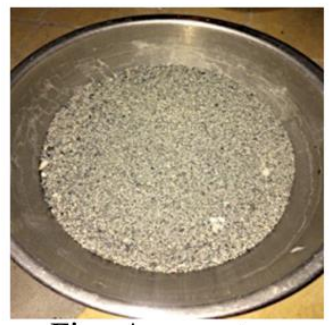

Fine Aggregate

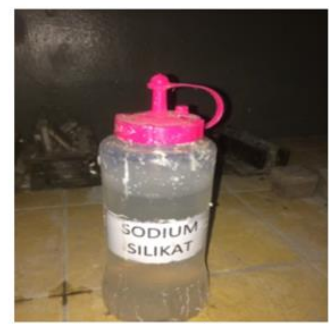

Sodium Silicate

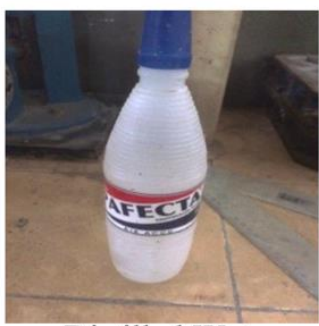

Distilled Water

Figure 1. Materials of Geopolymers Mortar

\subsection{Mix Design}

Variation of activator to binder ratio used in this research was $0.40,0.50$ and 0.60 in which were done based on trial mix and previous research, however Adam [8] suggested in her research that the dosage of $7 \%$ is needed to use in order to have optimum dosage of 0.40 .

For each mix, 6 specimens with 2 different treatments i.e. curing in the sulphate solution and in the water were prepared. The curing method was conducted in regard to ASTM C 267.

Three mixes were design for geopolymer mortar with additional lime and the variation of activator to binder ratio were $0.40,0.50$ and 0.60 respectively. Other 3 mixes were design 
without using lime with same variation of activator to binder ratio. One mix is a normal mortar regarding to SNI 03-6825-2002 that proportion of binder to fine aggregate is 1 to 2.75

\subsection{Mixing of geopolymer mortars}

1. Variation Fly ash, lime, and Sodium Hydroxide were put into a mixer bowl slowly and hand mixed for 30 second until evenly distributed.

2. Mixer mixing needs for \pm 4 minutes at speed of $140 \pm 5 \mathrm{rpm}$

3. Sodium silicate was then pour in the mixer bowl with a same speed for \pm 1 minutes.

4. Fine aggregate was continuously added into the mixing bowl and mix for \pm 1 minute

5. Additional water needs to add in and stirred for \pm 2 minutes.

6. The consistency of mortar is done by using flow table

\subsection{Casting and curing}

1. After flow table test, the mixture was put in the mixer bowl and mix at medium speed of $285 \pm 10 \mathrm{rpm}$ for 15 seconds.

2. The mortar is casted in a cube mould of $5 \mathrm{~cm}$ sides, and then vibrated using a vibrating table. The specimen, which is in the cube mould, is stayed at room temperature for 24 hours.

3. Demoulding of the mould is conducted.

4. Specimens without lime were then wrapped with wrapping plastic of 3 layers. Put in the oven to dry for 20 hours and oven temperature of $90^{\circ}$

\subsection{Sulphate solution immersion}

At the age of 28 days, one set of three geopolymers mortar specimens were immersed in 5\% sulfuric acid solution for the period of with age of $0,7,14,28,56$, and 84 days, and the compressive strength tests were conducted at the end of each immersion period accordingly. Another set of specimens were immersed in water for comparison.

\section{Results and discussion}

\subsection{Compressive Strength of geopolymer mortar in sulphate solution}

The compressive strength and the loss of strength of specimens immersed in sulphate solution is presented in Table 1 and 2 respectively.

As shown in Table 2, the percentage of strength loss of geopolymer mortar for specimen made of both fly ash and lime with the immersed age of 7 days is approximately $10 \%$ up to $17.50 \%$. While it is compared to geopolymer mortar made of only fly ash, the compressive strength of mortar is reducing for approximately $17 \%$ up to $19 \%$. However, the compressive strength of cement mortar is only reducing for $4.70 \%$. After immersed for 84 days, the compressive of geopolymer mortar with lime, without lime, and cement mortar was reduced by $50 \%-67.8 \%, 42.8 \%-61.3 \%$ and $69.1 \%$ respectively.

Figure 2 shows that fly ash only mortar is stronger in sulphate environment than that of with lime. The reaction of mortar and sulphate is less as $\mathrm{CaO}$ content of this mortar is less. However, geopolymer made of lime tends to have much more $\mathrm{CaO}$, mortar reaction of $\mathrm{CaO}$ and sulphate will be existed continuously until totally diminished of $\mathrm{CaO}$. This is also happened on the cement mortar as having a numerous $\mathrm{CaO}$ content. The reducing 
compressive strength of this mortar is significant (Figure 2), thus the drop in compressive strength of mortar is solely dependent on $\mathrm{CaO}$ content as sulphate ion will react with $\mathrm{CaO}$.

Table 1. Compressive strength of geopolymer mortar

\begin{tabular}{|c|c|c|c|c|c|c|}
\hline \multirow{2}{*}{ Mix } & \multicolumn{7}{|c|}{ Compressive strength (MPa) } \\
\cline { 2 - 7 } & $\mathbf{0 ~ d a y s}$ & $\mathbf{7}$ days & $\mathbf{1 4}$ days & $\mathbf{2 8}$ days & $\mathbf{5 6}$ days & $\mathbf{8 4}$ days \\
\hline D0,40C5W0,36 & 16,67 & 14,13 & 10,67 & 8,40 & 7,73 & 5,47 \\
\hline D0,50C5W0,34 & 14,67 & 13,20 & 11,73 & 9,87 & 9,20 & 7,33 \\
\hline D0,60C5W0,32 & 19,07 & 15,73 & 12,93 & 11,60 & 9,47 & 6,13 \\
\hline D0,40C0W0,36 & 19,47 & 16,13 & 11,60 & 9,47 & 8,67 & 7,73 \\
\hline D0,50C0W0,34 & 21,33 & 17,60 & 13,60 & 11,60 & 9,87 & 8,27 \\
\hline D0,60C0W0,32 & 20,27 & 16,40 & 15,60 & 14,27 & 13,73 & 11,60 \\
\hline Mortar Semen & 19,87 & 18,93 & 16,93 & 11,20 & 8,40 & 6,13 \\
\hline
\end{tabular}

Table 2. Strength losses after immersion at sulphate solution

\begin{tabular}{|c|c|c|c|c|c|c|}
\hline \multirow{2}{*}{ Mix } & \multicolumn{7}{|c|}{ strength losses after sulphate immersion (\%) } \\
\cline { 2 - 7 } & $\mathbf{0}$ days & $\mathbf{7 ~ d a y s}$ & $\mathbf{1 4}$ days & $\mathbf{2 8 ~ d a y s}$ & $\mathbf{5 6}$ days & $\mathbf{8 4}$ days \\
\hline D0,40C5W0,36 & 0,00 & $-15,20$ & $-36,00$ & $-49,60$ & $-53,60$ & $-67,20$ \\
\hline D0,50C5W0,34 & 0,00 & $-10,00$ & $-20,00$ & $-32,73$ & $-37,27$ & $-50,00$ \\
\hline D0,60C5W0,32 & 0,00 & $-17,48$ & $-32,17$ & $-39,16$ & $-50,35$ & $-67,83$ \\
\hline D0,40C0W0,36 & 0,00 & $-17,12$ & $-40,41$ & $-51,37$ & $-55,48$ & $-60,27$ \\
\hline D0,50C0W0,34 & 0,00 & $-17,50$ & $-36,25$ & $-45,63$ & $-53,75$ & $-61,25$ \\
\hline D0,60C0W0,32 & 0,00 & $-19,08$ & $-23,03$ & $-29,61$ & $-32,24$ & $-42,76$ \\
\hline Normal Mortar & 0,00 & $-4,70$ & $-14,77$ & $-43,62$ & $-57,72$ & $-69,13$ \\
\hline
\end{tabular}

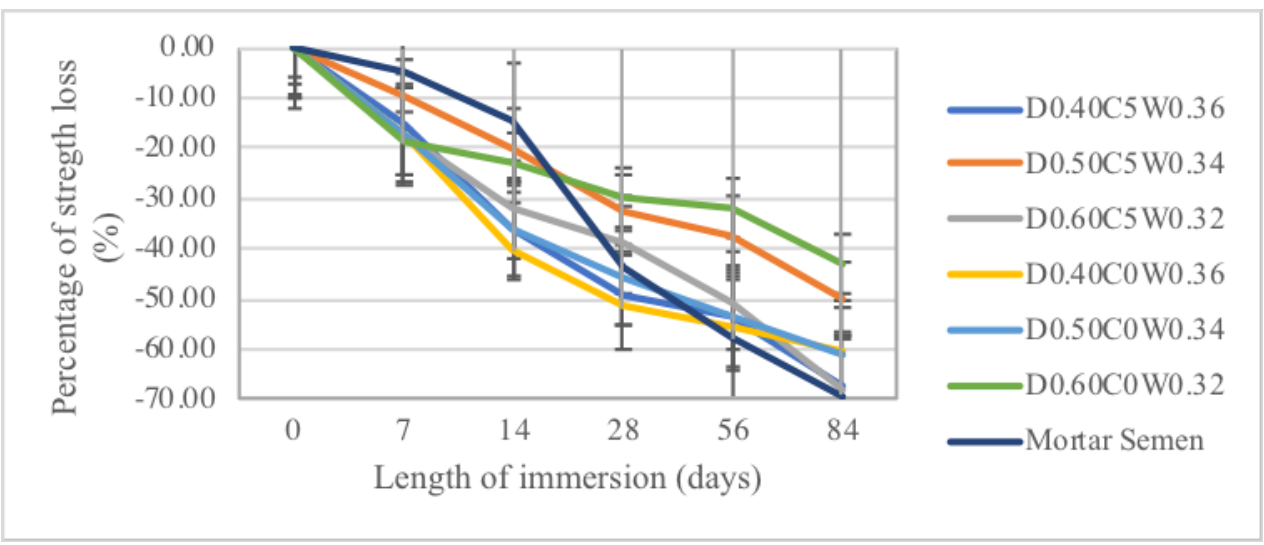

Figure 2. Compressive strength loss of geopolymer mortar specimens immersed in sulphate solution

\subsection{Compressive Strength of geopolymer mortar in sulphate solution}

Contrary to the sulphate immersion, it can be seen from Figure 3 that compressive strength growth of the geopolymer mortar made of fly ash and lime in 84 days water immersion tends to have an increase of $14.7 \%-46.4 \%$, but for geopolymer mortar without lime and cement mortar is only $3.1 \%-5.3 \%$, and $18,8 \%$ respectively.

It is a different behavior compared to the immersed mortar in the sulphate solution that of 7 days immersion age tends to decrease the compressive strength. In this point, the polymerization process is disrupted by existing of additional water. When the additional water contacts with mortar, reaction exists between water and sodium $(\mathrm{Na})$ and as a consequence the concentration of $\mathrm{Na}$ content decreases. 
Table 3. The increase compressive strength of geopolymer mortar in water immersion

\begin{tabular}{|c|c|c|c|c|c|c|}
\hline \multirow{2}{*}{ Mix } & \multicolumn{6}{|c|}{ strength increase of mortar after water. immersion (\%) } \\
\cline { 2 - 7 } & $\mathbf{0}$ day & $\mathbf{7}$ days & $\mathbf{1 4}$ days & $\mathbf{2 8}$ days & $\mathbf{5 6}$ days & $\mathbf{8 4}$ days \\
\hline D0,40C5W0,36 & 0,00 & 4,00 & 0,80 & 5,00 & 12,80 & 20,00 \\
\hline D0,50C5W0,34 & 0,00 & 38,18 & 2,73 & 13,64 & 39,09 & 46,36 \\
\hline D0,60C5W0,32 & 0,00 & 13,29 & 6,29 & 4,90 & 14,69 & 14,69 \\
\hline D0,40C0W0,36 & 0,00 & 17,12 & 6,85 & 3,42 & 1,37 & 4,79 \\
\hline D0,50C0W0,34 & 0,00 & 18,75 & 12,50 & 7,50 & 1,87 & 3,13 \\
\hline D0,60C0W0,32 & 0,00 & 19,74 & 13,16 & 4,61 & 0,66 & 5,26 \\
\hline Cement mortar & 0,00 & 3,36 & 2,01 & 11,41 & 15,44 & 18,79 \\
\hline
\end{tabular}

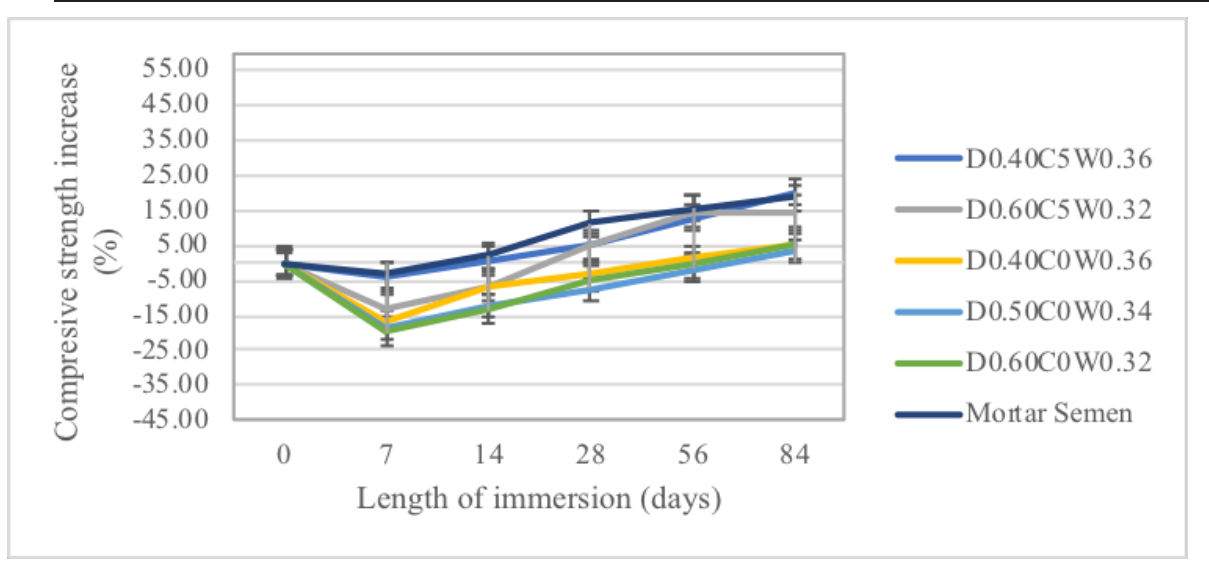

Figure 3. Compressive strength loss of geopolymer mortar specimens immersed in water

The leaching process is happened in which the $\mathrm{Na}$ is dissolved away from the mortar. When $\mathrm{Na}$ (alkali metal) content in the geopolymer mortar is decreased, the compressive strength of mortar is decreased as well. In the point of 14 until 84 days, the compressive strength increases again as polymerizations still continuously happened by existing $\mathrm{CaO}$ from lime and existing silicate from fly ash. The result of this polymerizations (C-H-S formation) will fill in the mortar pores.

\section{Conclusion}

1. The optimum compressive strength is happened for mix design with activator and binder ratio of 0.60 in the mortar on the basis of fly ash during immersion in the sulphate solution.

2. The optimum compressive strength is happened for mix design with activator and binder ratio of 0.50 in the mortar on the basis of both fly ash and lime during immersion in the sulphate solution.

3. During the immersion of mortar in sulphate solution, the weight of mortar tends to decrease as the increase of the immersion age. An opposite trend of the mortar immersed in the water, the weight of the mortar still increases as the age of immersion.

4. Mortar made of lime and fly ash with immersion of sulphate solution tends to have lower decreasing of compressive strength value compared to that of cement mortar. However, all mortar with immersion in the water is to have an increasing compressive strength. 


\section{Acknowledgement}

The authors would like to acknowledge The Ministry of Research and Higher Education for the financial support for this project under the scheme of Penelitian Dasar 2019.

\section{References}

1. V. C. Prabha and V. Revathi, "Geopolymer Mortar Incorporating High Calcium Fly Ash and Silica Fume, ” Arch. Civ. Eng., vol. 65, no. 1, pp. 3-16, 2019.

2. A. Z. W. Wazien, M. M. A. B. Abdullah, R. Abd Razak, M. A. Z. M. R. Rozainy, and M. F. M. Tahir, "Strength and Density of Geopolymer Mortar Cured at Ambient Temperature for Use as Repair Material," in IOP Conference Series: Materials Science and Engineering, 2016, vol. 133, no. 1.

3. S. M. Laskar and S. Talukdar, "A study on the performance of damaged RC members repaired using ultra-fine slag based geopolymer mortar," Constr. Build. Mater., vol. 217, pp. 216-225, 2019.

4. A. Suleiman, "Physical Sulphate Attack on Concrete," no. May, pp. 1-127, 2014.

5. P. Sun and H.-C. Wu, "Chemical and freeze-thaw resistance of fly ash-based inorganic mortars," Fuel, vol. 111, no. 0, pp. 740-745, 2013.

6. J. Prasad, D. K. Jain, A. K. Ahuja, and C. Dioxide, "Factors Influencing the Sulphate Resistance of Cement Concrete and Mortar," vol. 7, no. 3, pp. 259-268, 2006.

7. D. W. Law, A. A. Adam, T. K. Molyneaux, and I. Patnaikuni, "Durability assessment of alkali activated slag (AAS) concrete,” Mater. Struct. Constr., vol. 45, no. 9, pp. 1425-1437, 2012.

8. A. A. Adam, T. A. Nurdin, S. Maricar, and F. Amir, "The Effect of Sand to Binder Ratios and the Dosage of Activators on the Compressive Strength of Ambient Cured Fly Ash Based Geopolymer Mortar," in The 1st Conference on Engineering and Applied Science, 2016, pp. 75-80. 